\title{
BMJ Open Temporal trend in socioeconomic inequalities in the uptake of cancer screening programmes in France between 2005 and 2010: results from the Cancer Barometer surveys
}

\author{
David Mark Kelly, ${ }^{1}$ Carla Estaquio, ${ }^{1}$ Christophe Léon, ${ }^{2}$ Pierre Arwidson, ${ }^{2}$ \\ Hermann Nabi ${ }^{1,3,4,5}$
}

To cite: Kelly DM, Estaquio C, Léon C, et al. Temporal trend in socioeconomic inequalities in the uptake of cancer screening programmes in France between 2005 and 2010: results from the Cancer Barometer surveys. BMJ Open 2017;7:e016941. doi:10.1136/ bmjopen-2017-016941

- Prepublication history for this paper is available online. To view these files, please visit the journal online (http://dx.doi. org/10.1136/bmjopen-2017016941).

Received 30 March 2017 Revised 8 November 2017 Accepted 9 November 2017

CrossMark

${ }^{1}$ Département Recherche en Sciences Humaines et Sociales, Santé Publique, Épidémiologie, Institut National du Cancer, Billancourt, France

${ }^{2}$ Santé publique France, SaintMaurice, France

${ }^{3}$ INSERM, Centre for Research in Epidemiology and Population Health, Villejuif, France

${ }^{4}$ Faculté de Pharmacie,

Université Laval, Québec,

Canada

${ }^{5}$ Centre de Recherche du CHU de Québec-Université Laval, Québec, Canada

Correspondence to

Dr Hermann Nabi;

Hermann.Nabi@inserm.fr

\section{ABSTRACT}

Objectives Cancer screening is a form of secondary prevention for a disease which is now the leading cause of death in France. Various socioeconomic indicators have been identified as potential factors for disparities in breast, cervical and colorectal cancer screening uptake. We aimed to identify the socioeconomic inequalities, which persisted in screening uptake for these cancers, and to quantify these disparities over a 5-year period.

Setting The Cancer Barometer was a population-basedsurvey carried out in 2005 and 2010 in France.

Participants A randomly selected sample of participants aged 15-85 years ( $n=3820$ in 2005 and $n=3727$ in 2010) were interviewed on their participation in breast, cervical and colorectal cancer screening-programmes and their socioeconomic profile.

Primary and secondary outcome measures For each type of screening programme, we calculated participation rates, $\mathrm{OR}$ and relative inequality indices (RII) for participation, derived from logistic regression of the following socioeconomic variables: income, education, occupation, employment and health insurance. Changes in participation between 2005 and 2010 were then analysed.

Results Participation rates for breast and colorectal screening increased significantly among the majority of socioeconomic categories, whereas for cervical cancer screening there were no significant changes between 2005 and 2010. Rlls for income remained significant for cervical smear in $2005(\mathrm{Rll}=0.25,95 \% \mathrm{Cl} 0.13$ to 0.48$)$ and in 2010 (RII=0.31, 95\% Cl 0.15 to 0.64 ). Rlls for education in mammography ( $\mathrm{Rll}=0.43,95 \% \mathrm{Cl} 0.19$ to 0.98$)$ and cervical smear ( $\mathrm{Rl}=0.36,95 \% \mathrm{Cl} 0.21$ to 0.64 ) were significant in 2005 and remained significant for cervical smear ( $\mathrm{RII}=0.40,95 \% \mathrm{Cl} 0.22$ to 0.74 ) in 2010.

Conclusions There was a persistence of socioeconomic inequalities in the uptake of opportunistic cervical cancer screening. Conversely, organised screening programmes for breast and colorectal cancer saw a reduction in relative socioeconomic inequalities, even though the results were not statistically significant. The findings suggest that organised cancer screening programmes may have the potential to reduce socioeconomic disparities in participation.
Strengths and limitations of this study

- First study to examine temporal changes in inequalities for cancer screening uptake in France using relative inequality index.

- Benefits from datasets of two identical questionnaires on cancer screening uptake, taken 5 years apart, using two comparable population samples, hence minimising information bias.

- Evolution in the format of colorectal screening programme in terms of technique and age limits may have led to measured differences in uptake between 2005 and 2010.

- Residents of nursing homes and other medical institutions without a personal telephone line were excluded from the survey, limiting the generalisability of the findings.

- Relatively small sample for certain socioeconomic strata, reducing therefore the precision of some estimates.

\section{INTRODUCTION}

Screening for cancer is an important form of secondary prevention for a disease which is now leading cause of death in France and worldwide. ${ }^{1}$ The 2008 European report on cancer recommends that health systems focus their resources on cancer prevention and early detection rather than treatment alone, as the global disease burden of cancer threatens to become unsustainable in terms of financial costs, pressure on services, follow-up of patients and delivery of care. ${ }^{2}$

To date, many European countries have rolled out screening programmes for breast, colorectal and cervical cancer via mammography, faecal occult blood test (FOBT) and cervical smear, respectively. ${ }^{3}$ However, for these screening programmes to have a significant effect on reducing cancer mortality, 
they require a minimum level of participation among the eligible population; for instance, $70 \%$ for mammography, and $50 \%$ for FOBT. $^{5}$

We reviewed several publications from France, the UK, the USA, Italy, Denmark, Korea and Argentina, which identified variables shown to have a significant effect on cancer screening uptake. ${ }^{6-19}$ For breast cancer screening, various different social and economic variables were found to have a positive effect on uptake, including employment, higher occupation class, higher education level, income, private health insurance and car/home ownership. However, no single variable was consistently observed across the studies except for participation in other screening programmes. ${ }^{78}$ For cervical cancer screening, the variables identified as having a significant positive effect on uptake were more numerous, and notably consistent for income, ${ }^{711} 17$ higher education level, ${ }^{10-121718}$ employment $^{6121819}$ and private health insurance. $^{6} 718$ For colorectal screening, income was consistently shown to have a significant positive effect on uptake of screening across the studies. ${ }^{14} 1618$ Nevertheless, it remains unclear as to whether the effect of these socioeconomic variables on participation rates in screening programmes persists over time.

Only one study to date, drawn from the 2006, 2008 and 2010 French Healthcare and Health Insurance surveys, has examined the temporal evolution in breast, cervical and colorectal cancer screening uptake in France. ${ }^{6}$ This study conducted among 10000 participants found that those classified as unskilled workers were more likely to not have undergone cervical cancer screening $(\mathrm{OR}=1.64,95 \% \mathrm{CI} 1.38$ to 1.95$)$ when compared with those with an intermediate profession. The results also showed that women without ( $\mathrm{OR}=2.05,95 \%$ CI 1.68 to 2.51) or receiving free complementary health insurance $(\mathrm{OR}=1.79,95 \% \mathrm{CI} 1.36$ to 2.37$)$ were more likely to not have undergone breast cancer screening when compared with those with a private complementary health insurance. In this study, the authors found that inequalities for participation in breast and colorectal cancer screening persisted over the study period from 2006 to $2010 .^{6}$ Thus, we believe there is a need to re-examine how these trends may have evolved with respect to expansion in the coverage and awareness of organised cancer screening programmes. The third French National Cancer Plan for the 2014-2019 period has identified early detection of cancers as a primary priority. ${ }^{20}$ Included within this priority is the reduction of inequalities associated with cancer diagnosis, in the hope of subsequently reducing mortality rates. Any widening or reduction in socioeconomic inequalities in the uptake of screening programmes that are identified may then be used to direct future policy of the French national cancer control plan, which specifically seeks to address this issue. ${ }^{20}$ We aim therefore in the present study to identify the socioeconomic inequalities which persist for uptake of breast, cervical and colorectal cancer screening, and to quantify these disparities over a 5-year period in France.
MATERIALS AND METHODS

\section{Study population}

We used data, obtained with formal permission, from the Cancer Barometer surveys, two telephone surveys on cancer-related knowledge, attitudes and practices conducted by the French National Institute for Prevention and Health (now part of Santé Publique France). Both surveys were carried out on a representative random sample of the general French population aged over 16 years for the 2005 survey and aged 15-85 years for the 2010 survey. A two-stage random sampling design was used. Residents of nursing homes or other medical institutions who did not possess a personal telephone line were not included in the samples. Private households with telephones were included in the sample. The first sampling step was household selection (by phone number). Within each selected household, one French-speaking person aged 15-85 years was randomly selected using the 'next birthday' method. The study protocol included a formal request to participate, which explained the objectives of the study that was delivered by mail before the first telephone call. Informed consent was obtained at the start of the telephone interview, in accordance with the guidelines of the French Data Protection Authority (CNIL). The interviews were conducted using a computer-assisted telephone interview system.

In order to obtain adequate statistical power for measuring associations between variables and changes in participation rates at smaller levels, a sample size of between 3500 and 4000 was deemed appropriate. The 2005 Cancer Barometer sample consisted of 4046 participants aged over 16 years interviewed between April and June 2005. ${ }^{18}$ There were 226 individuals with missing observations in the 2005 Cancer Barometer sample, notably for all 3 of the dependent variables, and 7 out of 10 covariates and independent variables. These individuals terminated the survey prematurely, and were thus removed from the analysis as their data were not contributive, leaving 3820 participants in the sample population. Females $(51.5 \%)$ responded more often than males $(48.5 \%)$ and mean age of interviewees was 46.7 years. The 2010 Cancer Barometer sample consisted of 3727 participants aged 15-85 years interviewed during the first semester of $2010 .{ }^{19}$ The mean age was 44.6 years and the majority of participants were also female $(52.0 \%$ vs $48.0 \%)$. The response rates for the 2005 and 2010 Cancer Barometers were 51.2\% and $47.0 \%$, respectively.

\section{Measures}

Socioeconomic indicators (independent variables) were as follows: education level (inferior, equal to or superior to the baccalauréat (high-school diploma)), employment status (employed, unemployed and inactive), occupational class (farmer, self-employed, manager, professional, employee, manual worker, other), monthly income (below $€ 1000, € 1000-1500$, above $€ 1500$ ) and health insurance (private complementary vs basic insurance coverage). The outcome variables were 
participation in breast, cervical and colorectal cancer screening programmes (dependent variables). For breast cancer screening, participants aged over 40 years were asked if they had undergone mammography within the previous 2 years. For cervical cancer screening, participants aged over 20 years were asked if they had undergone a cervical smear within the previous 3 years. For colorectal cancer screening, participants aged 50-74 years were asked if they had undergone an FOBT within their lifetime. Covariates included gender, age, smoking status, alcohol consumption, region, living as a couple and having a close relative with cancer. For the calculation of screening participation rates, we added filters to select the target population eligible for each of the three different screening programmes. Breast screening by mammography $(\mathrm{n}=1546)$ : female gender and $49<$ age $<75$. Cervical screening by cervical smear $(n=3085)$ : female gender and $24<$ age $<66$. Colorectal screening by FOBT $(n=2647)$ : both genders where $49<$ age $<75$.

The weighting was based on the data of the 1999 and 2008 Employment Survey of the French population, ${ }^{21}$ taking into account age, gender, region, education level and number of persons per household. ${ }^{18}$ This allowed us to effectively calculate age-adjusted standardised rates for screening participation, in addition to later adjusting the regression models for the covariates mentioned.

\section{Statistical analysis}

We created a pooled dataset of the two surveys conducted in 2005 and 2010. We calculated age-adjusted screening rates (AAR) for each stratum using the weighting provided by the INPES. The temporal evolution in the participation rate within each stratum between 2005 and 2010 was examined by adding an interaction term for the year of the survey. The disparity within each socioeconomic variable was calculated as the absolute difference between the AAR for the highest and lowest group within an ordinal or binary variable for the given year.

ORs, derived from multiple logistic regression of screening participation on each socioeconomic variable were used as a measure of participation likelihood for each stratum of the six socioeconomic variables. The model was adjusted for the covariates: age, gender (colorectal screening only), region, alcohol, smoking, living as a couple and close relative with cancer. For categorical variables, the higher socioeconomic position was used as the reference group. The trend for disparities within each socioeconomic variable for each survey was then estimated and compared using a two-way interaction term composed of the socioeconomic variable of interest and a survey year dummy variable (2010 vs 2005), consistent with the methodology of previous studies on the topic. $^{22} 23$

For the ordinal variables of income and education level, we calculated the relative inequality index (RII) as a measure of health inequality as described by Mackenbach and Kunst. ${ }^{24}$ Previous studies on health inequalities, including breast cancer screening uptake, ${ }^{49}$ employed a similar methodology for examining temporal evolutions within ordered socioeconomic strata. ${ }^{23} 25$ The trend in RII for each survey was estimated and compared using a two-way interaction term, composed of the socioeconomic variable of interest and a survey year dummy variable (2010 vs 2005). The RII is a regression-based measure that summarises the association between two variables. It is computed by ranking income and education values on a scale from the lowest, which is 0 , to the highest, which is 1 . Each income or education level value covers a range on this scale that is proportional to the number of participants who held that value and is given a new value on the scale corresponding to the cumulative midpoint of its range. The RII resembles relative risk in that it compares the probability of cancer screening uptake at the extremes of income and educational levels, but is estimated using the data on all income and education values and is weighted to account for the distribution of these values. Here, the RII was fitted using logistic regression models. An RII of 0.5 for example implies that participants in the most deprived group (those with lower incomes and educations levels) had a 50\% lower probability of cancer screening uptake when compared with those in the least deprived group (those with higher incomes and education levels). All statistical analysis was performed using SAS V.9.2.

\section{RESULTS}

Table 1 presents the demographic and socioeconomic characteristics of the study populations. The overall participation rates among the eligible populations for breast, cervical and colorectal cancer screening are shown in table 2. $\chi^{2}$ tests for the change in participation rates within each socioeconomic stratum between 2005 and 2010 are also included. For mammography, participation rates increased significantly $(\mathrm{P}<0.05)$ among all socioeconomic strata, with the exception of farmers, managers, manual workers, unemployed, those with basic health insurance and education level superior to the baccalauréat. For FOBT, participation rates increased significantly among all socioeconomic strata between 2005 and 2010, with the exception of the unemployed or those with an occupation classified as other. For cervical smear participation rates, there were no significant changes in participation rates among any of the socioeconomic strata, except for those without complementary health insurance, which increased significantly from $52.5 \%$ to $71.0 \%$ ( $\mathrm{P}=0.017$ ).

Table 3 shows the results of the logistic regression models for mammography participation on each socioeconomic variable separately, adjusted for covariates. In 2005, farmers, self-employed, employees and manual workers showed significantly reduced participation compared with managers, whereas in 2010 the association remained significant only for manual workers. In 2005 , those with an education level inferior to the baccalauréat (OR=0.57, 95\% CI 0.35 to 0.95$)$ showed significantly reduced participation compared with those with 
Table 1 Standardised ${ }^{*}$ distribution of study populations for 2005 and 2010 Cancer Barometer surveys, $\mathrm{P}$ value for $\chi^{2}$ test

\begin{tabular}{|c|c|c|c|c|c|}
\hline \multirow[b]{2}{*}{ Variables } & \multicolumn{2}{|c|}{ Barometer $2005(n=3820)$} & \multicolumn{2}{|c|}{ Barometer 2010 (n=3727) } & \multirow[b]{2}{*}{$P$ value } \\
\hline & $\mathbf{n}$ & $\%$ & $\mathbf{n}$ & $\%$ & \\
\hline Gender & & & & & 0.660 \\
\hline Male & 1854 & 48.5 & 1790 & 48.0 & \\
\hline Female & 1966 & 51.5 & 1937 & 52.0 & \\
\hline Region & & & & & 0.976 \\
\hline Ile-de-France & 701 & 18.4 & 696 & 18.7 & \\
\hline West Paris basin & 380 & 10.0 & 348 & 9.3 & \\
\hline East Paris basin & 305 & 8.0 & 290 & 7.8 & \\
\hline North & 257 & 6.7 & 238 & 6.4 & \\
\hline West & 508 & 13.3 & 504 & 13.5 & \\
\hline East & 334 & 8.8 & 321 & 8.6 & \\
\hline South West & 414 & 10.9 & 412 & 11.1 & \\
\hline South East & 455 & 12.0 & 447 & 12.0 & \\
\hline Mediterranean & 457 & 12.0 & 471 & 12.6 & \\
\hline Occupation & & & & & $<0.001$ \\
\hline Farmer & 117 & 3.1 & 81 & 2.2 & \\
\hline Self-employed/craftsman & 220 & 5.8 & 270 & 7.2 & \\
\hline Manager/executive & 589 & 15.4 & 595 & 16.0 & \\
\hline Professional & 773 & 20.3 & 914 & 24.5 & \\
\hline Employee/office worker & 970 & 25.4 & 829 & 22.3 & \\
\hline Manual worker & 642 & 16.8 & 839 & 22.5 & \\
\hline Other & 506 & 13.3 & 199 & 5.3 & \\
\hline Education level & & & & & $<0.001$ \\
\hline Inferior $\mathrm{BAC}^{\star}$ & 1946 & 52.0 & 2270 & 61.2 & \\
\hline BAC & 651 & 17.4 & 635 & 17.1 & \\
\hline Superior BAC & 1146 & 30.6 & 803 & 21.7 & \\
\hline Monthly income & & & & & $<0.001$ \\
\hline$<€ 1000$ & 414 & 13.2 & 399 & 12.1 & \\
\hline$€ 1000-1500$ & 663 & 21.0 & 499 & 15.1 & \\
\hline$>€ 1500$ & 2075 & 65.8 & 2401 & 72.8 & \\
\hline Employment & & & & & $<0.001$ \\
\hline Employed & 2146 & 56.2 & 1851 & 49.7 & \\
\hline Unemployed & 177 & 4.6 & 260 & 7.0 & \\
\hline Inactive & 1497 & 39.2 & 1615 & 43.3 & \\
\hline Alcohol consumption & & & & & $<0.001$ \\
\hline Yes & 3430 & 89.8 & 3195 & 85.7 & \\
\hline No & 389 & 10.2 & 532 & 14.3 & \\
\hline Smoking status & & & & & $<0.001$ \\
\hline Yes & 964 & 25.2 & 1195 & 32.1 & \\
\hline No & 2856 & 74.8 & 2532 & 67.9 & \\
\hline Close relative with cancer & & & & & 0.950 \\
\hline Yes & 2366 & 62.1 & 2198 & 62.1 & \\
\hline No & 1446 & 37.9 & 1339 & 37.9 & \\
\hline
\end{tabular}

Continued 
Table 1 Continued

\begin{tabular}{|c|c|c|c|c|c|}
\hline \multirow[b]{2}{*}{ Variables } & \multicolumn{2}{|c|}{ Barometer $2005(n=3820)$} & \multicolumn{2}{|c|}{ Barometer $2010(n=3727)$} & \multirow[b]{2}{*}{$P$ value } \\
\hline & $\mathbf{n}$ & $\%$ & $\mathbf{n}$ & $\%$ & \\
\hline Living in couple & & & & & 0.071 \\
\hline Yes & 2465 & 64.6 & 2333 & 62.6 & \\
\hline No & 1351 & 35.4 & 1394 & 37.4 & \\
\hline Complementary health insurance & & & & & $<0.001$ \\
\hline Yes & 3518 & 92.6 & 3210 & 89.6 & \\
\hline No & 282 & 7.4 & 375 & 10.5 & \\
\hline Basic health insurance & & & & & 0.003 \\
\hline Yes & 361 & 10.2 & 441 & 12.4 & \\
\hline No & 3182 & 89.8 & 3109 & 87.6 & \\
\hline
\end{tabular}

*Weighted by age, gender, region and educational level according to standard population of the 1999 and 2008 Employment Surveys (INSEE).

BAC, Baccalauréat (high-school diploma).

an education level superior to the baccalauréat, which became non-significant in $2010(\mathrm{OR}=1.04,95 \% \mathrm{CI} 0.53$ to 2.05$)$.

Table 4 shows the results of the regression model for cervical smear participation for each socioeconomic variable. In 2005, significantly reduced participation was observed for self-employed and manual workers, which became non-significant for both in 2010. In 2005, there was significantly reduced participation for those earning $<€ 1000$ and $€ 1000-€ 1500$, which remained significant in 2010 for those earning $<€ 1000(\mathrm{OR}=0.47,95 \%$ CI 0.29 to 0.76$)$. An education level inferior to the baccalauréat showed significantly lower participation in both 2005 and in 2010. In 2005, being unemployed or inactive significantly reduced participation, and remained significant for both in 2010. The OR for cervical smear participation changed significantly $(\mathrm{P}=0.014)$ for those without complementary health insurance from 0.29 (95\% CI 0.17 to 0.49 ) in 2005 to 0.64 (95\% CI 0.38 to 1.08 ) in 2010. Having only basic health insurance was significantly associated with reduced participation in both periods.

Table 5 shows the logistic regression results for FOBT participation for each socioeconomic variable. Concerning occupation, manual workers $(\mathrm{OR}=0.63$, $95 \%$ CI 0.42 to 0.96 ) showed significantly reduced participation in 2010. ORs for all other occupations showed reduced participation compared with managers, but at a non-significant level in 2005 and 2010. Those earning $<€ 1000$ showed reduced participation in 2005 ( $\mathrm{OR}=0.62$, $95 \%$ CI 0.32 to 0.97 ), which became non-significant in 2010. There were no significant temporal changes in any of the ORs for participation in breast or colorectal cancer screening between 2005 and 2010.

The regression of screening participation on income distribution produced RIIs which can be found in tables 3-5. The results showed significant inequalities for cervical smear ( $\mathrm{RII}=0.25,95 \% \mathrm{CI} 0.13$ to 0.48 ) in 2005 , but not for mammography (RII=0.47, 95\% CI 0.19 to
1.29 ) or FOBT (RII $=0.70,95 \%$ CI 0.38 to 1.28 ). In 2010 , the income-based RII remained significant for cervical smear (RII $=0.31,95 \%$ CI 0.15 to 0.64 ). For education, mammography (RII=0.43, 95\% CI 0.19 to 0.98 ) and cervical smear (RII $=0.36$, 95\% CI 0.21 to 0.64 ) showed significant inequalities in 2005, whereas the RII for FOBT was non-significant (RII $=0.69,95 \%$ CI 0.42 to 1.14 ). In 2010, the education-based RII for mammography became non-significant (RII $=0.80,95 \%$ CI 0.26 to 2.50 ), whereas the RII for cervical smear remained significant (RII $=0.40$, $95 \% \mathrm{CI} 0.22$ to 0.74$)$. The $\mathrm{P}$ trend for the temporal change in the RIIs (adjusted model), measured by interaction term between 2005 and 2010, was non-significant for all three screening programmes for income and education level.

\section{DISCUSSION}

Our objective was to identify the socioeconomic inequalities which persisted in uptake of breast, cervical and colorectal cancer screening, and to quantify the disparities between socioeconomic groups between 2005 and 2010. In absolute terms, a significant increase in participation rates was observed for most socioeconomic strata for mammography and for FOBT between 2005 and 2010. Cervical cancer screening, however, saw no significant change in participation rates between 2005 and 2010 (except for those without complementary health insurance). A similar trend was observed when relative inequalities were considered. It should be noted that some of these inequalities persisted between 2005 and 2010 , even though formal statistical tests for trends were generally not significant.

\section{Findings in the context of the literature}

We found only one study to date that has examined the temporal evolution in breast, cervical and colorectal cancer screening uptake in France. ${ }^{6}$ Our objectives and 


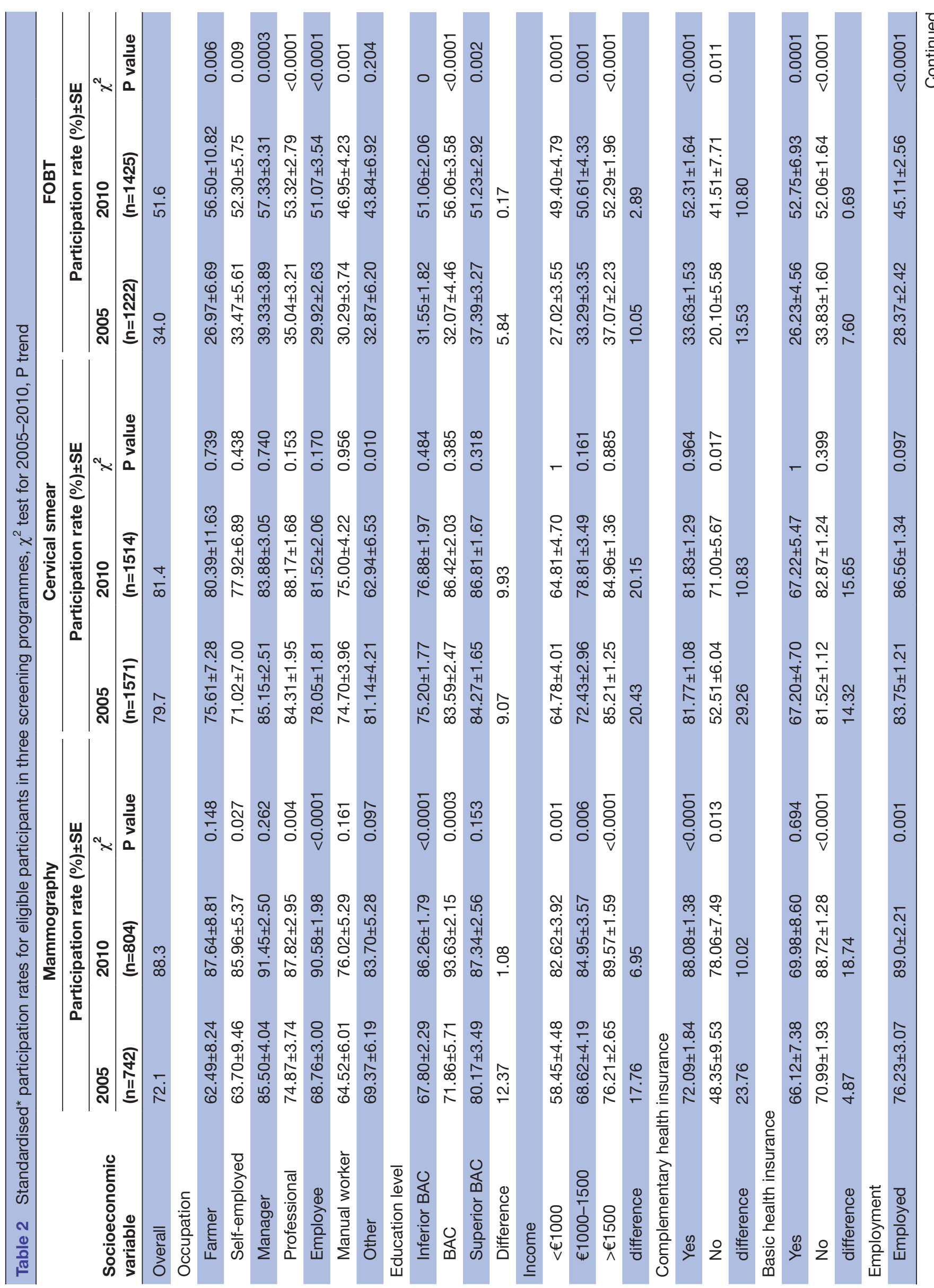


methods, however, constitute a major difference between our study and the one conducted by Sicsic and Franc. The latter aimed to analyse the obstacles to and levers for breast, cervical and colorectal cancer screening uptake and their trends over time, whereas the aim of our study was to identify the socioeconomic inequalities which persist in the uptake of breast, cervical and colorectal cancer screening, and to quantify these disparities over a 5 -year period. Thus, Sicsic and Franc pooled their three samples but did not conduct direct comparisons of associations between indicators of socioeconomic position and uptake of cancer screenings between periods.

The sole point of comparison between the two studies concerns the overall participation in screening programmes. Sicsic and Franc found that the screening rate for breast cancer decreased between 2006 and 2010, from $77.6 \%$ in 2006 to $74.0 \%$ in 2010 , but that the difference was not statistically significant. Although our study found an increase in participation rates for breast cancer screening, this was not statistically significant at the $5 \%$ level. They also found that colorectal cancer screening uptake increased significantly between 2006 and 2010, from $18.2 \%$ in 2006 to $38.9 \%$ in 2010 . This is consistent with our result showing that colorectal cancer screening uptake significantly increased from $34.0 \%$ in 2005 to $51 \%$ in 2010 . Finally, they found that the screening rate for cervical cancer significantly decreased from $75.3 \%$ in 2006 to $71.9 \%$ in 2010 . For cervical cancer, we found that the rate was stable between $2006(79.7 \%)$ and 2010 $(81.4 \%)$. In the end, differences in sampling, sample sizes, number of data collection phases and in desirability bias may explain these differences in participation rates. It should also be noted that the study by Sicsic and Franc was based on three surveys carried out in 2006, 2008 and 2010, with therefore a 2-year interval, whereas the Cancer Barometer survey was conducted at two points in time in 2005 and 2010. Our study confirmed significantly reduced participation for manual workers in breast and colorectal screening and for those with only basic health insurance in breast and cervical screening in 2010. This is consistent with the study by Sicsic and Franc which showed reduced participation in all three screening programmes for manual workers and those with only basic health insurance. Breast and colorectal cancer screening programmes saw the absolute differences in participation rates reduced over time for all socioeconomic variables in our study, with the exception of employment and basic health insurance. A study by Kim et al showed the disparity in mammography participation based on income remained unchanged among the American population, while the disparity based on education decreased from 2000 to 2005. ${ }^{9}$ There remains, however, a persistent disparity in participation rates in cervical cancer screening for the majority of socioeconomic variables in our study, consistent with the results of the studies by De Maio et al and Sicsic and Franc. ${ }^{6} 17$

The relative inequalities for income and education decreased for breast and colorectal cancer screening in 


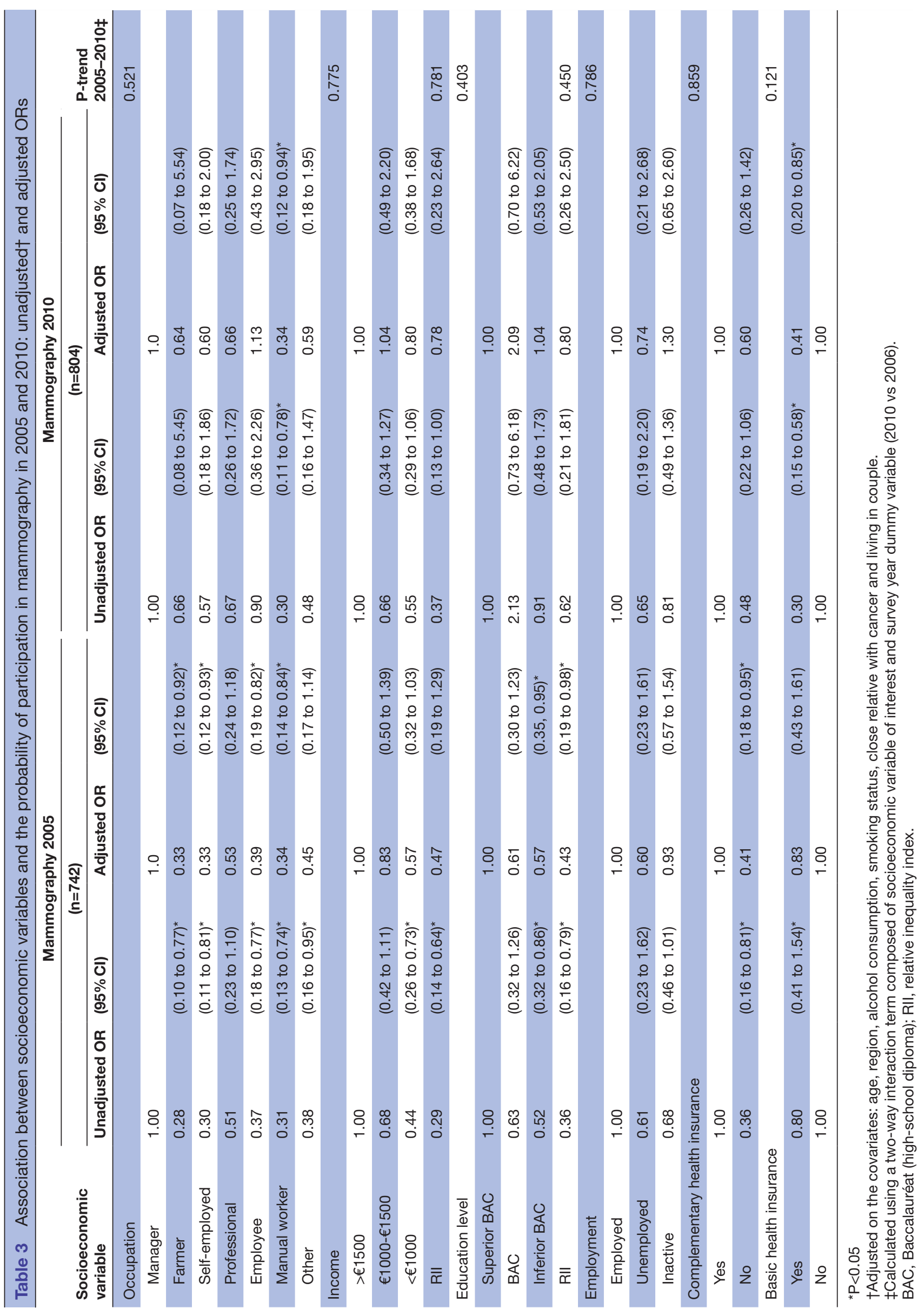




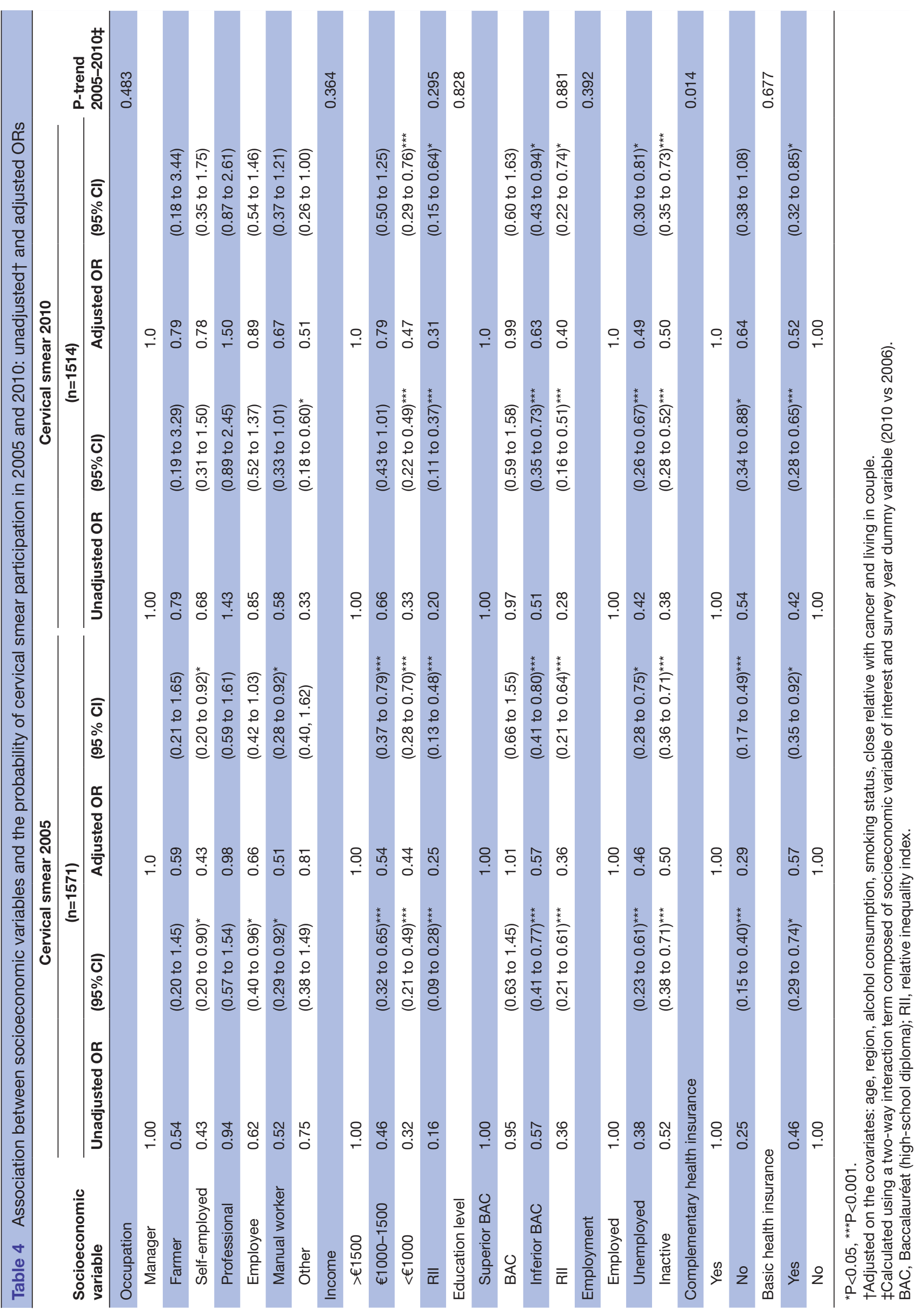

อิ่

익

을.

N

N్

¿

응 


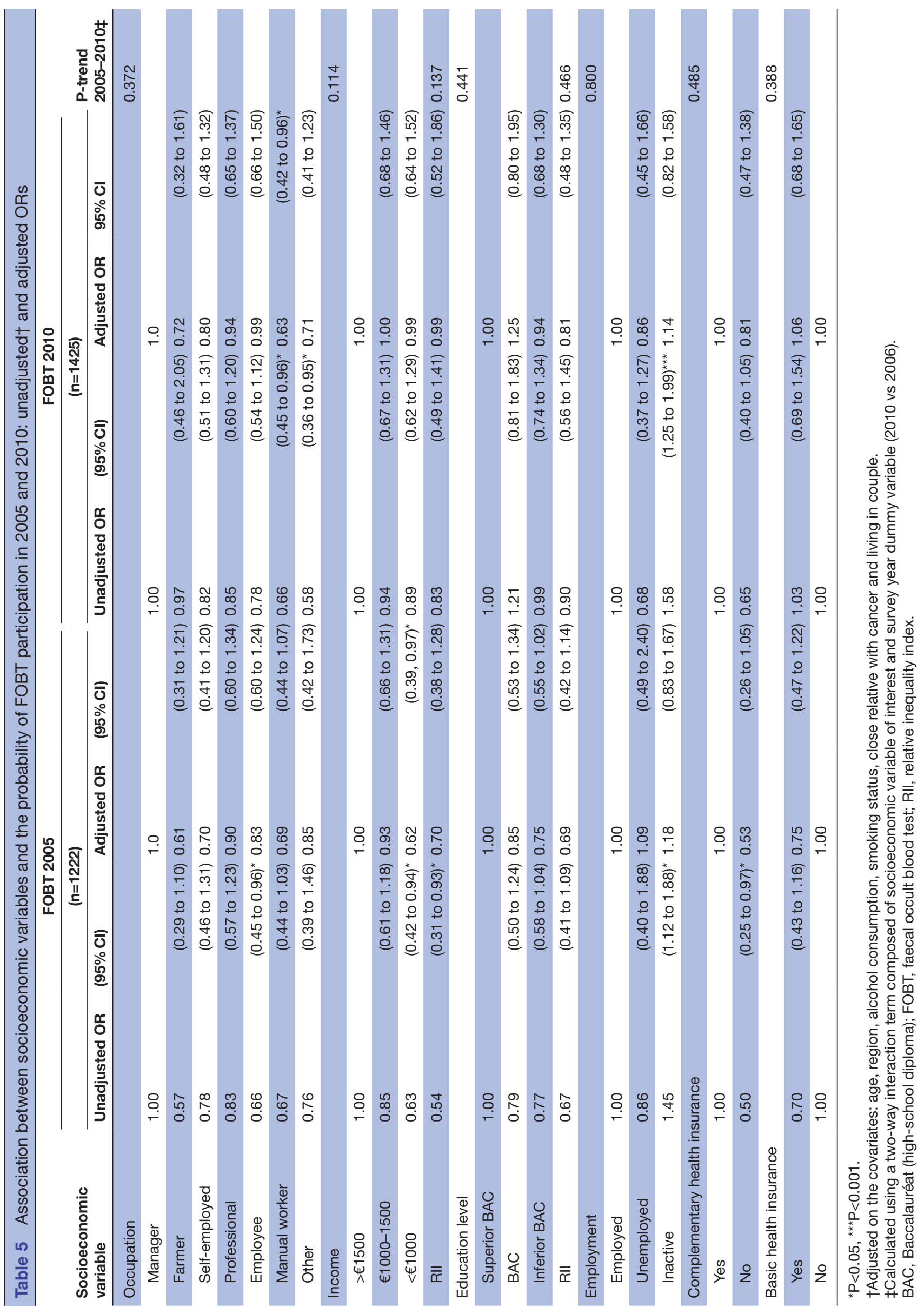


our study, although non-significantly. This is somewhat consistent with the study by De Maio $\mathrm{et} \mathrm{al}$, which showed a reduction in the RII for breast cancer screening from 2005 to $2009 .{ }^{17}$ In the study by Kim et al, the income-based relative inequalities tended to decrease slightly, while those for education remained constant over time. ${ }^{9}$ The relative inequalities for cervical cancer screening persisted according to both income and education from 2005 to 2010 in our study, both remaining statistically significant. This is partially consistent with the study by De Maio et al, where the social gradient decreased for income and increased for education between 2005 and 2010. ${ }^{17}$

\section{Interpretation of results}

Breast and colorectal screening programmes are organised at a national level and differences in absolute participation rates and relative inequalities decreased over time for all socioeconomic variables. For both breast and colorectal screening, the ORs for manual workers showed reduced participation compared with managers in 2010. Education and occupation are strongly correlated, with manual workers having a higher proportion of participants with an educational level inferior to the baccalauréat $(85 \%)$ than any other occupational category in 2010. Thus, they may have been less aware of the health marketing campaigns for colorectal cancer screening and the recommendation for FOBT, due to the negative effect of lower education on health literacy. ${ }^{14627}$

Cervical cancer remains without a nationally organised screening programme in France. It is the duty of doctors to organise and falls to the individual to pay for opportunistic screening via a cervical smear test. The lack of a nationally organised screening programme may impose significant financial, educational and cultural barriers to screening uptake among certain sections of the French population. The financial costs for a consultation and laboratory processing of the screening test may deter those with only basic health insurance, as public reimbursement covers only $70 \%$ of the cost. ${ }^{28}$ This may account for the persistence of the observed differences in participation rates and large RIIs. Improving the awareness, affordability and access to cervical cancer screening should be prioritised in order to increase participation rates and reduce socioeconomic disparities.

\section{Limitations and strengths of the study}

Our study used two almost identical datasets to construct a temporal analysis of participation in screening programmes in France between 2005 and 2010. The use of relative inequality indices in our study has never before been employed as a measure of the evolution of socioeconomic inequalities in cancer screening in the French population. The comparability of the study populations minimised selection bias and the conservation of the questionnaire format minimised information bias.

The study still retains several limitations however. It shares the usual shortcomings of telephone surveys. There is a potential selection bias, as residents of nursing homes or other medical institutions who did not possess a personal telephone line were not included in the samples. The study includes only those who are Frenchspeakers, excluding individuals unable to answer fluently in French. There were no available data on the ethnicity or nationality of participants in the study, which may have been an important source of confounding or effect modification. The exclusion of the above subpopulations, which are likely to be more socioeconomically disadvantaged, may have overestimated the screening participation rates in our study.

Our study used two separate sample populations, whose distributions in table 2 differed significantly for all of the socioeconomic indicators and several covariates. The difference in sample distributions may have accounted for the observed differences in screening participation rates. Thus, we cannot rule out that reductions observed in inequalities over time are not simply due to changes in socioeconomic distributions rather than an actual reduction in social inequalities in screening participation.

Changes in screening policies concerning age limits, screening techniques and regional access meant that the 2005 and 2010 Cancer Barometers were not directly comparable for certain programmes. The question of screening participation for colorectal cancer was therefore limited to the lifetime use of FOBT. Organised cervical screening was available in 13 regions in 2009, a source of regional variation not present in 2005. Some screening techniques are more memorable for patients, due to the invasiveness of the screening technique or the duration of the screening interval, which may have led to recall bias.

The respective analytical sample sizes in 2005 and 2010 for breast $(n=742, n=804)$, cervical $(n=1571, n=1514)$ and colorectal $(n=1222, n=1425)$ cancer screening may have been too small to capture disparities among socioeconomic strata, leading to a low precision of estimates. Missing observations for each variable accounted for $<5 \%$ of the total population, except for the variable income (16.3\% missing in 2005 and $9.3 \%$ in 2010). This may have limited the precision of certain estimates, producing participation rates with large standard errors and ORs with large CIs. We undertook multiple comparisons in our study. Thus, we cannot exclude that some of the results we have observed are due to chance.

\section{CONCLUSION}

The findings suggest that organised cancer screening programmes may have the potential to reduce socioeconomic disparities in participation.

Acknowledgements This article uses data collected from the 2005 and 2010 Barometre cancer studies, provided by the National Institute for Prevention and Health Education, INPES (now Santé Publique France). Special thanks to the department of screening at the Institut National du Cancer (INCA).

Contributors HN conceived the study, advised on methodology, reviewed the results of statistical analyses and supervised the final edit of the manuscript. DK reviewed the background literature, run statistical analyses and drafted the 
manuscript. CE, CL, PA provided advice on methodology and statistical analyses. CL and PA directed the data collection. All authors contributed to the final draft of this manuscript.

Funding The data collection was funded by the National Institute for Prevention and Health Education, INPES (now Santé Publique France) in association with the French National Cancer Institute (INCa).

Competing interests None declared.

Ethics approval CNIL.

Provenance and peer review Not commissioned; externally peer reviewed.

Data sharing statement All data presented in this manuscript came from two original datasets of the 2005 and 2010 Cancer Barometer surveys. The original files can be requested by contacting Santé Publique France (formerly INVS and INPES) via Pierre Arvidson (pierre.arwidson@santepubliquefrance.fr) or Christophe Léon ( christophe.leon@santepubliquefrance.fr).

Open Access This is an Open Access article distributed in accordance with the Creative Commons Attribution Non Commercial (CC BY-NC 4.0) license, which permits others to distribute, remix, adapt, build upon this work non-commercially, and license their derivative works on different terms, provided the original work is properly cited and the use is non-commercial. See: http://creativecommons.org/ licenses/by-nc/4.0/

(C) Article author(s) (or their employer(s) unless otherwise stated in the text of the article) 2017. All rights reserved. No commercial use is permitted unless otherwise expressly granted.

\section{REFERENCES}

1. Fitzmaurice C, Dicker D, Pain A, et al. The global burden of cancer 2013. JAMA Oncol 2015;1:505-27.

2. Albreht T, McKee M, Alexe DM, et al. Making progress against cancer in Europe in 2008. Eur J Cancer 2008:44:1451-6.

3. Eurostat. Breast cancer screening statistics. http://ec.europa.eu/ eurostat/statistics-explained/index.php/Breast_cancer_screening_ statistics (accessed $15 \mathrm{Jul} 2017$ ).

4. Palència L, Espelt $A$, Rodríguez-Sanz $M$, et al. Socio-economic inequalities in breast and cervical cancer screening practices in Europe: influence of the type of screening program. Int J Epidemiol 2010;39:757-65.

5. Institut National du Cancer. Calendrier du dépistage des cancers. http://www.e-cancer.fr/publications/84-outils-medecins-traitants/ 764-calendrier-du-depistage-des-cancers (accessed 15 Jul 2017).

6. Sicsic J, Franc C. Obstacles to the uptake of breast, cervical, and colorectal cancer screenings: what remains to be achieved by French national programmes? BMC Health Serv Res 2014;14:465.

7. Duport N, Serra D, Goulard H, et al. Which factors influence screening practices for female cancer in France?. Rev Epidemiol Sante Publique 2008;56:303-13.

8. Pornet C, Dejardin O, Morlais F, et al. Socioeconomic determinants for compliance to colorectal cancer screening. A multilevel analysis. $J$ Epidemiol Community Health 2010;64:318-24.

9. Kim J, Jang SN. Socioeconomic disparities in breast cancer screening among US women: trends from 2000 to 2005. J Prev Med Public Health 2008;41:186-94.
10. Kristensson JH, Sander BB, von Euler-Chelpin M, et al. Predictors of non-participation in cervical screening in Denmark. Cancer Epidemiol 2014;38:174-80.

11. Menvielle G, Richard JB, Ringa V, et al. To what extent is women's economic situation associated with cancer screening uptake when nationwide screening exists? A study of breast and cervical cancer screening in France in 2010. Cancer Causes Control 2014;25:977-83.

12. Damiani G, Federico B, Basso D, et al. Socioeconomic disparities in the uptake of breast and cervical cancer screening in Italy: a cross sectional study. BMC Public Health 2012;12:99.

13. Moser K, Patnick J, Beral V. Inequalities in reported use of breast and cervical screening in Great Britain: analysis of cross sectional survey data. BMJ 2009;338:b2025.

14. Kobayashi LC, Wardle J, von Wagner C. Limited health literacy is a barrier to colorectal cancer screening in England: evidence from the english longitudinal study of ageing. Prev Med 2014;61:100-5.

15. Leuraud K, Jezewski-Serra D, Viguier J, et al. Colorectal cancer screening by guaiac faecal occult blood test in France: Evaluation of the programme two years after launching. Cancer Epidemiol 2013;37:959-67.

16. Choi KS, Jun JK, Lee HY, et al. Increasing uptake of colorectal cancer screening in Korea: a population-based study. BMC Public Health 2010:10:265.

17. De Maio FG, Linetzky B, Ferrante D. Changes in the social gradients for Pap smears and mammograms in Argentina: evidence from the 2005 and 2009 National Risk Factor Surveys. Public Health 2012;126:821-6.

18. INCa, INPES. Baromètre cancer 2005. http://www.inpes.sante.fr/ Barometres/BaroCancer2005/ouvrage/index.asp (accessed 30 Jun 2016).

19. INCa, INPES. Baromètre cancer 2010. http://www.inpes.sante.fr/ Barometres/BaroCancer2010/index.asp (accessed 30 Jun 2016).

20. Institut National du Cancer. Le Plan cancer 2014-2019. http://www. e-cancer.fr/accueil-incanet/plan-cancer/plan-cancer-2014-2019 (accessed 30 Jun 2016).

21. INSEE. Enquête emploi 2008. www.enquete-emploi.insee.fr (accessed 30 Jun 2016).

22. Perez Ferrer C, McMunn A, Rivera Dommarco JA, et al. Educational inequalities in obesity among Mexican women: time-trends from 1988 to 2012. PLoS One 2014;9:e90195.

23. Khang YH, Yun SC, Lynch JW. Monitoring trends in socioeconomic health inequalities: it matters how you measure. BMC Public Health 2008;8:66.

24. Mackenbach JP, Kunst AE. Measuring the magnitude of socioeconomic inequalities in health: an overview of available measures illustrated with two examples from Europe. Soc Sci Med 1997;44:757-71.

25. Keppel K, Pamuk E, Lynch J, et al. Methodological issues in measuring health disparities. Vital Health Stat 2 2005;2:1-16.

26. Dolan NC, Ferreira MR, Davis TC, et al. Colorectal cancer screening knowledge, attitudes, and beliefs among veterans: does literacy make a difference? J Clin Oncol 2004;22:2617-22.

27. Ricardo-Rodrigues I, Jiménez-García R, Hernández-Barrera V, et al. Adherence to and predictors of participation in colorectal cancer screening with faecal occult blood testing in Spain, 2009-2011. Eur J Cancer Prev 2015;24:305-12.

28. Le dépistage par frottis cervical - Ameli. Quelle prise en charge par I'assurance maladie? Ameli. http://www.ameli.fr/professionnels-desante/medecins/vous-former-et-vous-informer/prevention-prise-encharge-par-I-assurance-maladie/prevention-du-cancer-du-col-de-Iuterus/le-depistage-par-frottis-cervical.php (accessed 30 Jun 2016). 